\title{
Non-users' trade-off between natural scenery, water quality, ecological functions and biodiversity conservation: a way to preserve wetlands
}

\begin{abstract}
The inclusion of both non-use values and values placed by non-users provide more reliable results about the real values of wetlands. A choice experiment method was conducted to estimate the willingness to pay for environmental conservation in non-users' communities adjacent to the Shadegan International Wetland (SIW) in Iran. A random parameter logit (RPL) model was developed to derive the marginal value and compensating surplus of the respondents for five attributes of the non-market values of SIW. The trade-off between five different wetland attributes showed that water quality improvement and biodiversity conservation were the most highly valued attributes. The results demonstrated that about $66 \%$ of non-users were willing to donate money for the contribution in SIW conservation, suggesting that non-users have the potential to contribute to SIW conservation programs.
\end{abstract}

Keyword: Non-users; Choice experiment; Random parameter logit; Shadegan International Wetland; Compensating surplus 